\title{
APORTACIÓN AL CONOCIMIENTO DE LA SOCIEDAD DE LA COSTA DE LA ULTERIOR EN ÉPOCA REPUBLICANA Y JULIO-CLAUDIA. EL REGISTRO $\delta$ EN LOS TITULI PICTI DE LAS ÁNFORAS SALSARIAS DE CASTRA PRAETORIA
}

\author{
LÁZARO LAGÓSTENA BARRIOS \\ Universidad de Cádiz
}

\begin{abstract}
El análisis de ciertos registros epigráficos conservados sobre ánforas béticas de salazones, procedentes del depósito documentado por Dressel en los fosos de los Castra Praetoria, nos permite plantear algunas reflexiones relativas a la composición y función de determinados sectores de la sociedad del litoral bético en la primera mitad del siglo I d.C. y sus precedentes republicanos. Los elementos onomásticos que se analizan tienen la particularidad de hallarse conectados a una actividad de gran importancia en las comunidades de esa época y espacio: la producción y el comercio de alimentos derivados del mar.
\end{abstract}

The analysis of several inscriptions preserved on Baetican amphorae of salted fish and fish sauce, which came from the find documented by Dressel in pits of Castra Praetoria, provides an insight into the composition and function of certain sectors of society on the Baetican coast in the first half of the 1 st century A.D., and their Republican precedents. The onomastic elements analyzed are characterized by being connected to an activity that was very important for the communities of that time and place: producing and selling processed sea food.

\section{EL DEPÓSITO DE LOS CASTRA PRAETORIA Y SU DATACIÓN}

En 1878 realizó Dressel una excavación en el nuevo barrio de Castro Pretorio. Tal actuación documentó parte de un depósito compuesto por una gran cantidad de ánforas, muchas de las cuales conservaban inscripciones pintadas, constituyendo, en opinión de Dressel, tras las halladas en Pompeya editadas en el C.I.L. IV por Mau, el mayor depósito con estas características conocido por la ciencia hasta aquella fecha. Estas ánforas se hallaron dispuestas bocabajo, en filas de hasta seis hiladas de altura. Formalmente mostraban una gran variedad, siendo el origen de la famosa tabla morfológica diseñada por el autor que sentó las bases de los estudios anfóricos.

Algunos de estos envases ofrecían dataciones consulares que permitieron establecer hitos para la cronología del conjunto: la más antigua se dató en el consulado de $L$. Scribonius Libo y L. Sempronius Atratinus, en el año 34 a.C.; la más reciente sólo conserva una alusión a uno de los cónsules, Corvinus, siendo posible identificarlo con un titular del 31
a.C. o bien con uno del 45 d.C., datación esta última preferida por el editor por razones paleográficas. Otras dataciones consulares del depósito remiten a los años 25 a.C., 13 a.C., 22 d.C. y 36 d.C.

La funcionalidad de este depósito fue explicada por Dressel por las necesidades de relleno y drenaje provocadas por la humedad del terreno, que propuso identificar con el foso del antiguo agger Serviano, y su construcción sería realizada en un solo momento, aunque los envases ofrecieran una amplitud de 79 años entre el más antiguo y el más reciente, de entre aquellos que portaban la data consular (Zevi, 1966, 211, siguiendo a Tchernia, 1964, 425 ss., propone ampliar ligeramente la cronología dada la presencia en el depósito de un sello de $C$. Antonius Quietus).

El año 45 d.C. constituye pues el terminus post quem para la creación del depósito y Dressel se inclinó por los años centrales de la primera centuria para situar el momento de la realización del relleno anfórico. Las ánforas que nos interesan para nuestro análisis - Dressel $7,8,9$ y 10 , en sus formas canónicas o similese insertan bien, por lo que conocemos en sus 
áreas de producción, entre las dataciones contempladas para el depósito, pero son propias de la etapa final augústea y toda la fase JulioClaudia, por lo que los registros pintados que conservan deben ser considerados grosso modo pertenecientes a la primera mitad de la primera centuria de la era (Dressel, 1879, 3640; 192-195)

Dado que los vestigios epigráficos presentes sobre estos envases fueron analizados antes de que se tuviera un conocimiento, siquiera aproximado, de las áreas de producción alfarera de los mismos, resultan comprensibles las dificultades que halló Dressel para su definición morfológica. La investigación posterior ha demostrado la gran variedad formal que presentan estos recipientes; los contenidos documentados en los mismos y las cronologias del depósito, entre otras razones, permiten defender su origen bético.

\section{LA EPIGRAFÍA ANFÓRICA PINTADA Y LA INTERPRETACIÓN DEL REGISTRO ä}

Fue también Dressel pionero en la ordenación de los tituli picti que ocasionalmente aparecian sobre los vestigios anfóricos. Para abordar su análisis propuso la descomposición del epígrafe pintado en diversos campos o registros, cada uno de ellos con una posición sobre el envase, con una caracterización y con un significado propio, designados como $\alpha, \beta, \gamma$, $\delta$ y $\varepsilon$ (C.I.L. XV, 560-565).

Dentro de la generalidad de este tipo de evidencia epigráfica, dos de sus aspectos deben ser, a mi juicio, resaltados para una correcta comprensión: el significado -y por tanto la interpretación- de un titulus pictus puede variar según el contenido del envase en que se encuentra; y algunos de los campos que lo componen cambian en su desarrollo y en su contenido a lo largo del tiempo; en ese sentido participan lógicamente del propio proceso histórico.

Una ordenación cuantitativa de los tituli picti conservados, que atienda al producto alimenticio transportado en los envases empleados como soporte epigráfico, muestra el predominio de los relacionados con las actividades olearias. Equiparados en un segundo plano se sitúan los rótulos pintados sobre ánforas vinarias y aquellos sobre las que contuvieron derivados de pescado

Fueron los epigrafes de las ánforas olearias, clasificadas por Dressel con el núme- ro 20, los mayoritarios de entre los compilados en el volumen XV del C.I.L., y los que mayor influencia ejercieron en la propuesta metodológica elaborada por el editor para el propio análisis de este tipo de vestigios epigráficos, aunque paradójicamente en el depósito de los Castra Praetoria fueran mayoría las formas $7 /$ 11 (Zevi, 1966, 240). Este predominio de los testimonios sobre envases olearios ha resultado perjudicial para el conocimiento y la interpretación de la epigrafía pintada relacionada con otro tipo de envases, particularmente para los que contuvieron salsas y conservas de pescado. Recientes propuestas tienden a paliar estas deficiencias atendiendo a la sistematización de la información contenida en estos vestigios epigráficos (Martínez Maganto, 2000, 1207 ss.)

Desde fines del siglo XIX, filólogos e historiadores valoraron la información presente en los tituli picti sobre las ánforas salsariasconserveras: su registro $\alpha$, a diferencia de los propios de las ánforas olearias, contenia, a la manera de nuestras etiquetas comerciales, preciosas informaciones sobre los productos culinarios, elaborados para el comercio por los establecimientos conserveros en época alto imperial (Corcoran, 1957, 145-160; Jardin, 1960, 70 ss.; Zevi, 1966, 208 ss.; Curtis, 1979, 1-62).

Ha sido la historiografía reciente la que ha revalorizado la información onomástica contenida en otros campos del titulus: los registros $\beta$ amplían paulatinamente nuestra nómina de mercatores y negotiatores (Corcoran, 1958, 69; Jardin, 1960; Zevi, 1966, 234 ss.; Étienne, Mayet, 1998a, 212-213; Étienne, Mayet, 1998b, 153-155), los registros $\gamma$ hacen lo propio con aquellos receptores de la mercancía en su destino y controladores del proceso de distribución final (Zevi, 1966, 217, nota 29; Etienne, Mayet, 1998a, 214-215).

El último de los campos epigráficos que puede ofrecer una información onomástica útil, el registro $\delta$, ha recibido menos atención, por razones que expondremos a continuación.

Dressel identificó sobre las ánforas del Testaccio el campo $\delta$ : a parte dextra prope ansam oblique titulus litteris cursivis, continens nomina varia, notas, consules (C.I.L. XV, p. $560)$. Entre sus elementa: nota $R$ (barrada); oppidi nomen; numerorum genera varia; vocabulum in-num vel-ese desinens; nomen viri vel mulieris secundo casu enuntiatum; nomina servilia primo casu posita; figlinarum nomen; consules; ocurrunt praeterea vocabula 
breviata incertae interpretationis (C.I.L. XV, p. 561).

Desde las propuestas del C.I.L. XV, condicionadas por el peso específico de los envases olearios en el conjunto, como ya indicamos, se tendió a identificar el registro $\delta$ como el vestigio del control fiscal sufrido por los envases en circulación. Así Dressel indicaba: ex iis quae de titulis litteris cursivis prope ansam scriptis hucusque iam recte mihi videor statuere posse, eos non ad privatam, sed ad publicam administrationem esse referendos.

Nótese, al enumerar los elementa, la consideración conjunta de los tituli que el editor muestra, pues trata bajo el mismo epígrafe los elementos que encuentra tanto en envases olearios, como vinarios o salsarios, aunque indicando que no todos los elementos se hallan al tiempo en los registros. Dressel no estableció diferencia en sus hipótesis según el posible producto contenido en cada ánfora. Además manejó testimonios similares pertenecientes a la I, II y III centuria, siendo consciente de la diversidad de situaciones que estos reflejaban. Sí sugirió con agudeza: possunt enim nonnullae, eae imprimis quae antiquioris aetatis sunt, etiam pertinere ad commercium privatum (C.I.L. XV, p. 564).

Los registros $\delta$ fueron pues considerados como vestigios del control fiscal, independientemente del ánfora que lo portase y del producto que ésta contuviera. A ello contribuyó además que los más antiguos conocidos sobre envases olearios que, a juzgar por su evolución posterior (Remesal, 1986, 22; Aguilera, $2000,1231-1240)$, si reflejan ese control fiscal, responden a un formulario muy simple:

\section{nombre en caso genitivo + arca + numeral + nombre en caso nominativo.}

Igualmente simple, como expondremos, son los registros $\delta$ conservados sobre los ejemplares anfóricos salsarios coetáneos.

Desde las propuestas de Dressel, diversos investigadores se han inclinado por interpretar los registros $\delta$ sobre ánforas salsarias como vestigios del control fiscal y la onomástica presente en ellos como alusiones a los acceptores responsables del mismo (Zevi, 1966, 233-234; Manacorda, 1977, 121 ss.). Los argumentos empleados fueron, además de los aportados por Dressel: la desconexión de la onomástica de este registro con las restantes del envase; su presencia sobre envases de tipología diversa (aunque toda ella destinada a los productos piscicolas); y la distribución por diversos mercatores de envases que muestran a un mismo individuo en sus registros $\delta$.

Los editores del pecio de Port-Vendres II plantearon una hipótesis distinta para la interpretación de los registros $\delta$ sobre envases conserveros. Aludirían a los productores o propietarios del contenido del envase. Criticaron la propuesta de Dressel identificando como serviles a los individuos presentes en este registro, defendieron que considerándolos productores se cumplian igualmente las premisas de Zevi y además se aclaraban situaciones particulares, como la presencia de personajes femeninos en algunos registros (Colls, Étienne, Lequement, Liou, Mayet, 1977, 93 ss.; Étienne, Mayet, 1998a, 213-214). En otra ocasión nos hemos inclinado por compartir esta segunda opinión (Lagóstena, 2001, 286), a la que creo se pueden añadir algunos elementos explicativos que la corroboran.

En tal sentido cabe argumentar que un mejor conocimiento de los centros de producción de los envases pesquero-conserveros béticos del periodo que nos ocupa, demuestra que es habitual en ellos la producción conjunta y coetánea de ánforas de tipología variada, destinadas en su mayor parte a los derivados piscícolas (Lagóstena, 1996, passim, con la bibliografía anterior), por lo que su presencia, también conjunta y coetánea, en las mismas factorías conserveras y en los mismos depósitos anfóricos generados por el consumo, es también lógica, como ya observara Zevi (1966, 231).

Por otra parte es suficientemente conocida la composición de los cargamentos de los navíos de época Julio-Claudia, y múltiples los ejemplos que demuestran cómo de la carga pueden participar diversos negotiatores o mercatores, que pueden comerciar con un mismo producto, procedente de una misma región productora. Pero, además, esta estructura comercial de los primeros decenios de la era coincide, a grandes rasgos, en su composición y características con la que hubo de existir en los ambientes productores, es decir entre el sector de propietarios de las industrias conserveras, como podemos inferir de las tipologías que presentan muchos conjuntos documentados por la arqueología (Lagóstena, 2001, 295)

Que los elementos onomásticos del registro $\delta$ no muestren conexión con otros presentes en el envase puede ser explicado por una de las características generales de la eco- 
nomía de la época, que tiene su origen en la consideración social de las actividades agrícolas, pero que bien pudo proyectarse sobre otras actividades productoras. Me refiero a la aparente desconexión entre los agentes de la producción y los agentes de la distribución, que hablan de esferas de la economía interdependientes pero bien delimitadas en lo que afecta a los intereses y a la consideración de los individuos participantes. Esta circunstancia, unida a las deficiencias de las muestras -el limitado número total conocido de tituli picti- dificulta no sólo la conexión aludida, sino cualquier otra conexión onomástica entre todos los elementos epigráficos presentes en un mismo envase.

Por otra parte, el formulario, supuestamente fiscal, presente en los envases Dressel 20 de los Castra Praetoria no se refleja en ninguno de los registros $\delta$ legibles, presentes sobre envases piscícolas del mismo depósito, como argumentaremos a continuación.

Los elementos epigráficos de estos envases fueron recopilados por Dressel bajo el epigrafe Amphorae in quibus fuit garum, liquamen, muria, halec, y comprendía desde el número 4686 al 4806 del C.I.L. XV. De ellos sólo veinte muestran $\delta$ legibles.

En estos aparecen nombres, a veces abreviados (C.I.L. XV, 4711, 4719, 4736, 4737 , $4749,4750,4760$ ), pero cuando están desarrollados se muestran en genitivo (C.I.L. XV, 4720 , $4731,4732,4741,4756)$. También se hallan numerales, solos (C.I.L. XV, 4700, 4735, 4740, 4757,4759 ) o con S final (C.I.LXV, 4733, 4782). Finalmente, en algún caso hay en posición $\delta$ una alusión al contenido (C.I.L. XV, 4782).

Los registros $\delta$ de las ánforas piscícolas de los Castra Praetoria no parecen obedecer pues a un formulario fiscal, como sí lo muestran las olearias que coexistían en el mismo depósito.

Generalmente reflejan una onomástica, simple, aunque en ocasiones la fórmula se alarga para indicar la condición del individuo firmante, como en el caso de ( )sti Lucil( ) $S($ ), que Dressel propuso interpretar como la denominación de un individuo, cuyo nombre ignoramos, siervo de Lucilius (C.I.L. XV, 5753). Todos los casos onomásticos, cuya lectura se ofrece completa, los hallamos declinados en genitivo.

El resto de los elementa parece relacionarse con características del producto contenido en el envase: la cantidad en aquellos numerales más elevados; quizás su precio en otros que finalizan con la letra S; en un caso el producto mismo: abdomina membratim caesa (C.I.L. XV, 4782; Plin. N.H. IX, 48).

Todo lo expuesto contribuye a confirmar que los datos registrados en los $\delta$ que nos ocupan son ajenos a cualquier formulario de tipo fiscal. Por otra parte los elementos como el peso bruto o neto del producto, la posible alusión a su valor de mercado, la alusión a la variedad alimenticia presente, todos ellos, aunque heterogéneos, se relacionan bien con los ambientes de la producción.

Los individuos presentes en estos registros deberían ser contemplados pues como agentes interesados en la producción pesqueroconservera bética. El análisis que sobre su onomástica podamos desarrollar ofrecería información sobre ese sector de la sociedad bética de época Julio-Claudia.

Sin embargo hay que reconocer que los argumentos expuestos por los partidarios de ambas hipótesis no son completamente decisivos, por lo que debemos esperar al hallazgo de nuevos testimonios para resolver en firme la cuestión.

Pero considerando los argumentos expuestos, tomando partido, en función de los mismos, por la hipótesis que identifica a los individuos presentes en los registros $\delta$ como propietarios-productores de las salsas y conservas de pescado béticas, hallaríamos en esta fuente un camino para superar el mayor obstáculo, indicado por la historiografía (Curtis, 1991, 148-158), que dificulta el conocimiento de los aspectos y los intereses sociales que existieron tras la industria durante la primera mitad del siglo I d.C., empleando para ello el análisis de esta onomástica.

\section{ANÁLISIS ONOMÁSTICO Y RASGOS SOCIA- LES}

En la siguiente tabla recopilamos los datos de los quince tituli picti del depósito que conservan el registro $\delta$ y que constituyen la base documental de nuestro análisis onomástico.

La primera observación que debemos realizar, ya indicada por otros autores como recordábamos en páginas precedentes, es la existencia de situaciones personales variadas, si atendemos a la onomástica de los individuos firmantes en los registros $\delta$. Si los identificamos como officinatores o possessores de diversas cetariae béticas del periodo, debemos 


\begin{tabular}{|c|c|c|c|c|c|}
\hline \multicolumn{6}{|c|}{ Tituli Picti sobre ánforas Hispánicas de salsas y salazones de pescado halladas in fossa aggeris ad Castra Praetoria. } \\
\hline Referencia & Forma & Alfa & Beta & Gamma & Delta \\
\hline CIL XV, 4711 & $\mathrm{Dr} .8$ & G(ari) $F($ los) & M. Quintilli Hermae & & Caecil(i) \\
\hline CIL XV, 4719 & Dr. 14 & Liq(uaminis) F(los) Excel(lens) & L. Purelli Gemelli & $M$ & Calpurn() $N x$ \\
\hline CIL XV, 4720 & Dr.10 & $L(i) q($ uaminis $) F($ los $)$ & A. Atil(i) Macri & & Lucani \\
\hline CIL XV, 4731 & Dr. 10 & $\mathrm{Ha}(\mathrm{lec}) \mathrm{S}$ (combri)? & lossipi Co(rneli)? & & (A) $\operatorname{sinini}$ \\
\hline CILXV, 4732 & Dr. 7 & $\operatorname{Cod}$ () Po() Dom() AlllIA LXXX & Dorionis L. D. Quieti & & Romani \\
\hline CIL XV, 4736 & Dr. 9 similis & Limp() Ve(tus) III & M. Porci Nymphodi & & Maced Qvo() \\
\hline CIL XV, 4737 & Dr.7 similis & Mal() & P. Cordi Grati & & Domestic() \\
\hline CIL XV, 4741 & Dr. 7 & P()Arg () V() Penuar()AllIA CXXV & M. Licini Mahetis & & Hesperi Dom()? \\
\hline$C / L X V, 4748$ & Dr.10 & (A) $/ I I A$ & P. Atti Severi & & Areti()? \\
\hline CIL XV, 4749 & Dr. 10 & () $v l^{\prime}$ & P. Atti (Sev)eri & & (Do)mestic() \\
\hline CIL XV, 4750 & Dr.10 similis & $C()$ & M. Baebi Clarici & & Domestic() \\
\hline CIL XV, 4753 & Dr. 9 similis & (AI) $\| A$ & QQ. C(ae)cilis & & () sti Lucill) s() \\
\hline CIL XV, 4756 & Dr. 10 similis & & C. Valeri Catulii & & Crani() \\
\hline CIL XV, 4760 & Dr. 10 similis & & & M. No() & Fall) \\
\hline CIL XV, 4782 & Dr. 9 similis & $A B D O M C$ & & IVlio Sci() & Abdo MC XXVIS \\
\hline
\end{tabular}

resaltar la existencia entre ellos de personas de condición ingenua y dependientes. Los primeros vendrían indicados, en ciertos casos, por una onomástica alusiva a su origo, mayoritariamente itálica, y en otros por la ostentación de nomina o cognomina propios de la ciudadanía romana. Entre los segundos se presentan onomásticas latinas que remiten a individuos de condición servil y, en algún caso, nombres de resonancia helénicas.

La nómina de individuos que muestran en su onomástica su origen itálico estaría compuesta por Lucanus, Romanus, Aretinus y Falernus, de aceptar, en este último caso, este desarrollo

El cognomen Lucanus, que puede ponerse lógicamente en relación con la región de Lucania, se muestra en la recopilación de Kajanto con ciento veintidós individuos de condición libre, frente a cuatro esclavos o libertos $(1982,193)$. Abascal atestigua veintiséis casos en Hispania $(1994,403)$, de los cuales dos se documentan en Cádiz (C.I.L. II, 1761, 1767), uno en Tarragona (C.I.L. II, 4165) y otro en Faro (C.I.L. II, 5139).

En el caso de Romanus, cognomen considerado servil por Dressel, Kajanto documenta trescientos doce individuos libres frente a cuarenta y uno cuya condición fue esclava o liberta $(1982,182$.) De los quince documentados en Hispania, uno lo es en Cádiz, dos en Tarragona y dos en Barcelona (C.I.L. II, 1877; 4219 y $4267 ; 4515$ y 4588 respectivamente).

Menos habitual resulta la onomástica Aretinus, o mejor Arretinus, cognomen alusivo a la ciudad de la Etruria oriental, mal representado en el C.I.L. en general y ausente en el volumen II.

Falernus puede ponerse en relación con sus homónimos alusivos al ager campano, la tribu o el mons. Frente a ocho de condición libre documentados epigráficamente, dos remitían a individuos de condición esclava (Kajanto, 1982, 189). En Hispania no se documenta.

Todos estos cognomina que aluden, al menos inicialmente, al origen geográfico de sus portadores, remiten a regiones de la Italia Occidental, a Campania, Etruria, Lucania y el Lacio. Sus portadores, según la recopilación de Kajanto, ostentan mayoritariamente una condición libre, aunque la servil no pueda ser completamente descartada

Aunque las cronologías del depósito anfórico de Castra Praetoria puedan ser posteriores a la colonización itálica oficial de la Bética, estos cognomina mencionados deben considerarse como vestigios epigráficos de tal fenómeno en la región. Cabe recordar aquí a A. Umbricius Scaurus, conocido personaje dedicado al negocio salsamentario en Pompeya, a quien se le han dedicado diversos estudios (Andreau, 1974, 296-299; Curtis, 1979a, 161 ss.; Curtis, 1979b, 5-23; Étienne, Mayet, 1991, 187 ss.). Umbricius porta como nomen la origo de sus antepasados, aunque su cognomen, por el pez escaro, alude a la actividad que le ha permitido promocionar, primero económicamente, luego socialmente: la venta de salsas de pescado. Aunque su negocio se desarrolle aún en época Flavia, su onomástica continúa indicando su origen umbro, y su antepasado bien pudo participar del fenómeno migratorio, aunque en los límites intraitálicos: de la Umbria a la Campania.

Podemos formar otro grupo con aquellos que presentan nomina propios de ciudadanos romanos. Ostentarian los gentilicios Caecilius, Calpurnius, Asinius y Granius; aunque dada la fragmentación de los epígrafes, o las abreviaturas empleadas en su ejecución, podemos res- 
tituirlos también como cognomina derivados de los mismos: Caecilianus, Calpurnianus, Asinianus y Granianus. En ambos casos estamos ante onomásticas propias de ingenuos, alusivas originariamente, como es bien sabido, a fenómenos de adopción, y a su asunción como cognomen derivado del nomen paterno o del patronus. Cabe concluir que estos personajes representados en nuestros registros $\delta$, además de libres, muestran conexiones con gentes extendidas $y$, al menos tres de ellas, bien representadas en la epigrafía hispana (Abascal, $1994,98-101$; 104-106; 85-86; 146-147) constituyendo en el caso de los Caecilii el octavo nomen más frecuente en Hispania (Abascal, 1994, 98).

Con una onomástica servil clara sólo se nos muestra el siervo de Lucilius, cuyo nombre no conservamos, y Domesticus, quien suscribe tres envases, pero que podría también identificarse, a juzgar por la parte del titulus conservada, con el propio siervo de Lucilius, restitución que permitiría precisar más las vinculaciones de este individuo. En Hispania se documentan cuatro ejemplos, dos de ellos en el litoral catalán (C.I.L. II, 4305; 6165; Abascal, 1994, 346). Los casos de Macedonius o Macedonicus y Hesperus pueden remitir tanto a individuos libres como serviles. Ambos se encuentran representados en la epigrafia hispana: el primero de ellos lo podemos hallar entre los vestigios del instrumentum domesticum (C.I.L. II, 4975, 38; Macen(-), en Abascal, $1994,49)$ y en femenino en un epígrafe de Fuentellana (C.I.L. II, 3229); cierto L. Vinuleius Hesper, procedente de Valencia se documenta en C.I.L. II, 3770 (Abascal, 1994, 386).

Sobre los doce individuos documentados. y con las prevenciones que han de derivarse de este tipo de análisis, ocho parecen ostentar una condición libre, de los cuales la mitad conservan indicios de su origo itálica, y la otra mitad, claras conexiones con gentilicios extendidos. Sólo dos parecen remitir con cierta nitidez a personajes esclavos; otros dos pueden encontrarse en una u otra situación.

Esta misma conclusión puede ser un argumento más para considerar los registros $\delta$ como indicios de la propiedad o la conducción de la industria conservera bética en los años centrales de la I centuria. A juzgar por los resultados, esta actividad no parece ser conducida preferentemente por individuos de condición servil, cuyas onomásticas escasean; más bien predominan los de condición libre y, en buena medida, aquellos herederos de las iniciativas emprendidas por los agentes de la colonización oficial itálica en tiempos de César y Augusto. La nómina es por otra parte relativamente amplia, dadas las características del conjunto, y remite a la propia pluralidad y fragmentación que la arqueologia atestigua para los complejos salazoneros del momento (Lagóstena, 2001, 294-295).

\section{LAS SALAZONES BÉTICAS Y LA MIGRA- CIÓN ITÁLICA}

Es posible que los testimonios de los Castra Praetoria muestren una imagen, ciertamente compleja, de la propiedad y la conducción de las industrias conserveras béticas a mediados del siglo I d.C. tal y como venimos defendiendo, por más que sea una imagen limitada y condicionada por la realidad de unos vestigios que deben entenderse como parte, no sabemos si administrada o privada, del abastecimiento a la capital del imperio.

Estos documentos nos sitúan ante las primeras alusiones a los posibles possessores de época Julio-Claudia, pero poco sabemos de la situación previa y de cómo se ha llegado a la configuración del panorama ofrecido por la nómina de los Castra Praetoria, así como del paso de una actividad, que en el litoral bético se hallaba, en los inicios de la fase Republicana, en manos de las oligarquías de las ciudades fenicias occidentales, a manos de quienes se documentan en el depósito romano. Ciertamente conocemos fenómenos similares en otros sectores económicos de la Ulterior, particularmente en el de la minería (Mangas, Orejas, 1999, 220-265, con la bibliografía anterior), e incluso se ha planteado la definición prerromana de la industria y, desde esta perspectiva, su proceso de integración en la órbita romana (López Castro, 1995, 116-119;160-173; Lagóstena, 2001, 203-221).

Quizá el interés itálico por las pesquerías sudhispánicas se manifestara tan pronto como las comunidades que las poseían entraron bajo el ordenamiento político romano; sin embargo son muy escasos los testimonios, arqueológicos o literarios, que permiten la necesaria demostración.

Puede ser un testimonio del libro noveno de Plinio, dedicado a los animales acuáticos, el que mejor ejemplifique los nuevos intereses que en el sector piscícola manifiesta el mundo itálico hacia finales del siglo II o principios del I a.C. Nos dice el autor: 
Ostrearum vivaria primus omnium Sergius Orata invenit in Baiano aetate L. Crassi oratoris, ante Marsicum bellum, nec gulae causa, sed avaritiae, magna vectigalia tali ex ingenio suo percipiens, ut qui primus pensiles invenerit balineas, ita mangonicatas villae subinde vendendo. is primus optimum saporem ostreis Lucrinis adiudicavit, quando eadem aquatilium genera aliubi atque aliubi meliora, sicut lupi pises in Tiberi amne inter duos pontes, rhombus Ravennae, murena in Sicilia, elops Rhodi, et alia genera similiter, ne culinarum censura peragatur. Nondum Britannica serviebant litora cum Orata Lucrina nobilitabat; postea visum tanti in extremam Italiam petere Brundisium ostreas, ac ne lis esset inter duos sapores, nuper excogitatum famem longae advectionis a Brundisio compascere in Lucrino.

Eadem aetate prior Licinius Murena reliquorum piscium vivaria invenit, cuius deinde exemplum nobilitas secuta est Philippi, Hortensi. Lucullus exciso etiam monte iuxta Neapolim maiore impendio quam villam exaedificaverat euripum et maria admisit, qua de causa Magnus Pompeius Xerxen togatum eum appellabat. N.H. IX, 168-170.

Plinio sitúa la eclosión de estas iniciativas emprendedoras en Italia antes del año 90 a.C., en tiempos del orador $L$. Crassus, antes de las Guerras Mársicas. No sabemos si el interés por la rentabilidad del sector piscicola, en su faceta criadora o transformadora, se manifestó previamente en las provincias hispánicas aunque, como veremos, algunos testimonios arqueológicos invitan a suponerlo.

Los personajes mencionados, Sergius Orata y Licinius Murena, portan ambos, al igual que mucho tiempo después Umbricius Scaurus, cognomina piscícolas como ostentación de sus fuentes de recursos (Varrón, Rust. III,3,10). Ambos destacan en el texto pliniano por ser portadores de una nueva mentalidad en relación con la cría de peces y moluscos en cautividad: sus vivaria son fuente de magna vectigalia y se alejan de la concepción predominante en las villae republicanas, que los contemplaba como muestra del lujo y el refinamiento de sus habitantes, asi como parte de la villatica pastio (Varrón, Rust. III,2,18). La gula ha dado paso, en palabras de Plínio, a la avaricia; según Varrón la frugalitas a la luxuria (Rust. III,3,6), la delectatio al fructus (Rust. III,4,2).

Las instalaciones construidas para el desarrollo de estas actividades productivas suponen el empleo de una inversión de capital no despreciable: Xerxen togatum llamó Pompeyo a Lucullus por la magnitud del canal que construyó para llevar agua marina a sus instalaciones, una obra que superaba en costo la edificación de una villa. Los importantes ingresos obtenidos justificaban la inversión. En el perfil de estos emprendedores se nos muestra su capacidad económica, elemento limitador del número de los mismos.

El ejemplo fue seguido por otros miembros de la nobilitas, como Philippus y Hortensius, manifestación clara de los nuevos intereses económicos que atraían al sector dominante de la sociedad romana, y que debe tenerse presente a la hora de indagar sobre quiénes participaron de la nueva economía hispana.

Ciertamente este cambio de mentalidad que afecta a la clase dirigente romana frente a los medios de enriquecimiento no era nuevo, se muestra como uno de los rasgos característicos de la Italia posterior a la Segunda Guerra Romano-Cartaginesa. El análisis de Gabba sobre el prefacio de la obra De Agri Cultura de Catón evidencia los nuevos resortes económi$\cos$, que se extienden de la agricultura hacia la mercatura marítima, con sus implicaciones financieras (Gabba, 1980, 91-93). Quizá las actitudes deploradas por Varrón como propias de los hombres de su generación (Rust. III,10), de las cuales se hace eco Plinio, supongan sólo un paso más en este camino, la manifestación de un interés por una fuente de riquezas que se aleja más de las que antaño fueron consideradas honorables: la crianza, con fines lucrativos, de peces y moluscos; y aún más, la transformación de productos marinos, una actividad que en el Mediterráneo Occidental era hasta entonces propia de las comunidades semitas.

Cabría cuestionarse cómo se manifestó este interés itálico sobre la tradicional industria pesquero-conservera hispánica y en qué fechas podemos comenzar a hallar testimonios que permitan profundizar en el análisis de tal proceso. Recientes hallazgos arqueológicos en el litoral andaluz pueden ponerse en relación con el mismo.

En el año 1997 se emprendió la excavación de una extensa zona artesanal ubicada en la Avenida Pery Junquera en San Fernando, Cádiz. El estudio preliminar mostró un espacio dedicado a la elaboración de envases cerámicos, principalmente ánforas de tradición púnica para el envasado de productos piscicolas. Las cronologías de la ocupación se prolongaban desde fines del siglo III hasta fines del II a.C. La cultura material mostraba una fase 
inicial de gran continuidad en relación con otros testimonios de esta actividad en la zona en época púnica. $Y$ una segunda fase que, manifestando indicios de cambio, conoce la irrupción de productos cerámicos itálicos, como envases Dressel 1 campano-laciales y cerámicas de barniz negro del mismo origen. Pero, como se destacó oportunamente, el elemento más significativo de esta última fase es un horno para la cocción cerámica, datado en los años centrales del siglo II a.C., cuya planta, dimensiones y técnica edilicia rompia completamente $-y$ físicamente- con la tradición local, respondiendo la nueva estructura fornácea a modelos itálicos republicanos (González, Torres, Lagóstena, Prieto, 2000, 175-185).

Los elementos itálicos introducidos en Pery Junquera no responden a una mera recepción de productos procedentes del comercio marítimo. Las nuevas estructuras de cocción deben interpretarse como una intervención directa de agentes itálicos sobre un sector artesanal que pocos cambios había conocido durante los cien años previos, un sector subsidiario de una actividad muy lucrativa, la producción de salsas y conservas de pescado.

Otra aportación similar se produce desde las recientes excavaciones de los niveles republicanos de las factorías conserveras de Baelo Claudia. Bajo los niveles de instalación de las cetariae altoimperiales se documentan vestigios de las tareas de transformación piscícola, a los que se asocia un conjunto de envases anfóricos completos. Entre estas ánforas se encuentran ejemplares que remiten, por sus características físicas y morfológicas y por las marcas selladas que ostentan, a las producciones de los talleres itálicos de Sestius, y otros de producción local que imitan a los anteriores hasta en pequeños detalles formales, alguno con grafitos latinos con ligaturas, indicio de una fabricación bética por manos de quien conocia bien los rudimentos de la escritura cursiva latina. A diferencia de los envases itálicos, las imitaciones locales contuvieron salsas de pescado. Estos niveles han sido datados en torno al 110-100 a.C. (Bernal, Arévalo, Lorenzo, Aguilera, 2003).

Los Sestii parecen haberse implicado en la producción y comercio de derivados piscícolas itálicos desde fines de la II centuria, como puede documentarse en el Portus Cosanus, respondiendo a una estrategia de diversificación de sus bases económicas, sustentadas hasta entonces principalmente en el vino (McCann, Bourgeois, Gazda, Oleson, Will,
1987, 339 ss.) ¿Proyectaron los Sestii estos intereses sobre la industria conservera del litoral gaditano? Los testimonios de Baelo así parecen sugerirlo.

Tales iniciativas no deben entenderse desde una percepción exclusivamente economicista, las ventajas políticas y sociales, la comunión de intereses entre el poder politico y la acción privada, la función política de la riqueza en palabras de Gabba (1980, 96-97) deben contemplarse en la explicación del fenómeno de ampliación de los ámbitos de acción de estos potentados sobre el litoral peninsular hispánico.

Nuevamente Plinio, cuya fuente en este caso fue Trebius Niger, miembro del comitatus del gobernador provincial L. Lucullus (Broungton, 1968, 454-457), puede ilustrarnos sobre la industria conservera del litoral bético en estas fechas (N.H. IX, 92-93), particularmente para un ámbito de un territorio tan significativo como el litoral gaditano, la ciudad de Carteia. La anécdota insertada en el libro dedicado a los animales acuáticos, las incursiones de un pulpo de dimensiones monstruosas sobre las cetariae de la ciudad, no debe desviar nuestra atención sobre un asunto de mayor trascendencia: ¿quiénes eran sus propietarios en una ciudad que conoce la implantación de una colonia latina desde el 171 a.C.?. Hemos indicado en páginas previas las noticias que Plinio dedica a los intereses piscícolas de los Luculli en Italia, a las cuales pueden agregarse las aportadas anteriormente por Varrón (Rust. III,2,17; III,3,10; III, 17,8).

Creo que los escasos testimonios disponibles ilustran sin embargo sobre los comienzos de la participación de elementos itálicos en la industria conservera sudpeninsular desde, al menos, los años centrales del siglo II a.C. Esta participación debe relacionarse con ese sector potentado de la sociedad itálica que emprende en la Campania similares iniciativas a fines de la centuria y principios de la siguiente. En el caso hispano y en estas fechas la posible incorporación itálica a estas actividades productivas muestra dos características destacadas: en primer lugar se realiza sobre ambientes de producción previos y consolidados, particularmente ámbitos urbanos, como Baelo y, quizás, Carteia, y espacios artesanales como los ligados a Gades; en segundo lugar, su intervención no produce aún una fractura o transformación aparente de los sistemas productivos imperantes. 
Falta aún deducir, a partir de futuras intervenciones arqueológicas que afecten a los correspondientes niveles republicanos, si esta situación que comienza a detectarse en significativos enclaves del entorno gaditano se reproduce en otros ambientes productores del litoral de la Ulterior. Además precisamos definir mejor los rasgos de los individuos que pueden representar los intereses de los potentados itálicos en las costas sudpeninsulares. Es imprescindible en tal sentido intentar una identificación nominal de los mismos que permita alimentar la restitución histórica de sus conexiones e intereses.

Parece que, al menos para ciertos ámbitos del litoral peninsular, cabe contemplar el móvil económico, además de los tradicionales políticos y militares, entre los que justifican la presencia itálica en Hispania, una presencia con intereses lucrativos que podria ser, en casos como el gaditano, anterior a las Guerras Sociales (Marin Diaz, 1988, 251 ss.). Pero evidentemente las tres facetas -la militar, la politica y la económica- se muestran interconectadas: los envases fabricados en Pery Junquera para el transporte de salsamenta se documentan entre los restos de los abastecimientos a las legiones que asedian Numancia, o en los niveles fundacionales de Valentia (Pascual, Ribera, 2000, 571-573), siendo estos los primeros vestigios del aprovisionamiento de productos piscícolas gaditanos a las legiones republicanas.

Entre esta situación, que parece iniciarse hacia mediados del siglo II a.C., y la reflejada en los testimonios del depósito de Castra Praetoria cabe destacar un nuevo factor histórico que explica la transición entre ambos: el impulso oficial dado a la colonización itálica de la Uiterior durante la segunda mitad del siglo I a.C.

Persisten las carencias en las fuentes literarias para abordar este aspecto del proceso, que sitúa a parte de este contingente migratorio como possessores de instalaciones de transformación piscícola en el litoral andaluz. Ignoramos los nombres de estos propietarios, aunque conocemos mejor cómo se ve afectada la subsidiaria manufactura cerámica que proporcionó los envases para la industria. Algunas características de esta migración, como la reestructuración del parcelario rústico de numerosas ciudades que se le asocia, la instalación de explotaciones agrícolas en las cuales se desarrollan manufacturas apropiadas, como las figlinae, y el espíritu emprendedor de este contingente humano privilegiado, ansioso de promocionar social y económicamente, se manifiestan con claridad en las campiñas gaditanas. Las numerosas alfarerías rústicas instaladas desde entonces elaboran nuevas series de ánforas, de inspiración grecoitálica, destinadas a las conservas de pescado. Todos estos asuntos han sido tratados por la historiografía reciente (López Castro, 1995, 160 ss.; Lagóstena, 1996, 126 ss.; García Vargas, 1998, 216-221; Lagóstena 2001, 270 ss.).

Debemos traer nuevamente a colación la onomástica del depósito excavado por Dressel: aquellos cognomina que denotaban la origo itálica de un tercio de los firmantes deben considerarse vestigios de lo que hubo de ser un fenómeno más extendido durante las últimas décadas del siglo I a.C. y las primeras del siguiente. Tal fenómeno alteraría no sólo los últimos vestigios de la ordenación púnica de la industria, también afectaría al perfil del propietario de las mismas y a las características de las inversiones itálicas en la producción de salsas y conservas de pescado béticas.

Los efectos de la colonización oficial sí transformaron definitivamente y en su totalidad los sistemas de producción anteriores, heredados del mundo púnico peninsular y paulatinamente filtrados en sus distintos sectores por la primera generación de itálicos que se interesó en estas actividades económicas. Tal transformación se manifestó como indicamos en el sector agrícola y manufacturero. También las industrias de salazones hubieron de conocer sus efectos. Los vestigios Julio-Claudios de los tituli picti analizados no son sino muestra de la culminación de esta trayectoria.

Prof. Lázaro Lagóstena Barrios
Área de Historia Antigua
Dpto. de Historia, Geografía y
Filosofia
Facultad de Filosofia y Letras
Avda. Dr. Gómez Ulla s/n
11003 Cádiz
lázaro.lagóstena@uca.es

\section{BIBLIOGRAFÍA}

ABASCAL PALAZÓN, J.M., 1994: Los nombres personales en las inscripciones latinas de Hispania, Anejos de Antigüedad y Cristianismo II, Murcia.

AGUILERA MARTIN, A., 2000: "Los tituli picti d del convento astigitano en el primer tercio del siglo III d.C.", Congreso Internacional Ex Baetica Amphorae, IV, Sevilla 1998, 1231-1240. Écija.

ANDREAU, J, 1974: Les affaires de Monsieur Jucundus. Collection de L'École Française de Rome, Roma. 
BERNAL, D., ARÉVALO, A., LORENZO, L. y AGUILERA, L., 2003: "Imitations of italic amphorae for fish sauce in Baetica. New evidences from the salt fish factory of Baelo Claudia (Hispania), Rei Cretariae Romanae fautorum, 38, 305-313.

BROUGHTON, T.R.S., 1968: The magistrates of the roman Republic, V. I, Michigan.

COLLS, D., ÉTIENNE, R., LEQUEMENT, R., LIOU, B. y MAYET, F., 1977: L'épave Port-Vendres /l et le commerce de la Bétique a l'époque de Claude, Archaeonautica 1, París.

CORCORAN, T.H., 1957: The roman fishing industry of the Late Republic and Early Empire, Michigan.

CORCORAN, T.H., 1958: "Pliny's garum castimoniarum", The Classical Bulletin, 34, 69.

CURTIS, R.I., 1979a: The production and commerce of fish sauce in the western roman empire. A social and economic study, Londres.

CURTIS, R.I., 1979b: "The garum shop of Pompei", Cronache Pompeiane, V, 5-23.

CURTIS, R.I., 1991: Garum and salsamenta. Production and commerce in materia medica, Leiden.

DRESSEL, H., 1879: "Di un grande deposito di anfore rinvenuto nel nuovo quartiere del Castro Pretorio", Bulletino della Commissione Archeologica Comunale, 36-195, Tav. VII-XVIII.

ÉTIENNE, R. y MAYET, F., 1991: "Le garum à la mode de Scaurus", Gerión, Homenaje al Dr. Michel Ponsich, 187194.

ÉTIENNE, R. y MAYET, F., 1998a: "Le garum a Pompéi. Production et commerce", Revue des Études Anciennes, 100, 199-215.

ÉTIENNE, R. y MAYET, F., 1998b: "Les mercatores de saumure hispanique", Mélanges de l'École Française de Rome. Antiquité, 110,1, 147-165

GABBA, E., 1980: "Riflessioni antiche e modene sulla attivitá commerciali a Roma nei secoli II e I a.C.", The seaborne comerse of ancient Rome: Studies in archaeology and history, MAAR XXXVI, 91-102. Roma.

GARCÍA VARGAS, E., 1998: La producción de ánforas en la Bahia de Cádiz en época romana (siglos II a.C. - IV d.C.), Écija

GONZÁLEZ, B., TORRES, J., LAGÓSTENA, L. y PRIETO,
O., 2000: "La producción anfórica en la bahía gaditana en época republicana: la intervención de urgencia en la Avda. Pery Junquera (San Fernando, Cádiz)", Congreso Internacional Ex Baetica Amphorae, I, Sevilla 1998, 175185. Écija.

JARDíN, C., 1961: "Garum et sauces de poisson de l'antiquité", Rivista di Studi Liguri, XXVII, 70-96.

LAGÓSTENA BARRIOS, L., 1996: Alfarería romana en la Bahía de Cádiz, Cádiz.

LAGÓSTENA BARRIOS, L., 2001: La producción de salsas y conservas de pescado en la Hispania Romana (II a.C. - VI d.C.). Col-lecció Instrumenta 11, Barcelona.

LÓPEZ CASTRO, J.L., 1995: Hispania Poena. Los fenicios en la Hispania romana, Barcelona.

MANACORDA, D., 1977: "Anfore spagnole á Pompei", Quaderni di Cultura Materiale, 1, 121-133.

MANGAS, J. y OREJAS, A., 1999: "El trabajo en las minas en la Hispania romana", J.F. Rodríguez Neila, C. González Román, J. Mangas, A. Orejas, El trabajo en la Hispania romana, 207-313. Madrid

MARÍN DÍAZ, A., 1988: Emigración, colonización y municipalización en la Hispania republicana, Granada

MARTINEZ MAGANTO, J., 2000: "Inscripciones sobre ánforas de salazón: interpretación sobre la estructura y significación comercial de los Tituli Pictr', Congreso /nternacional Ex Baetica Amphorae, IV, Sevilla 1998, 12071219. Écija.

MCCANN, A.M., BOURGEOIS, J., GAZDA, E.K., OLESON, J.P. y WILL, E.L, 1987: The roman port and fishery of Cosa, Princenton.

PASCUAL BERLANGA, G. y RIBERA LACOMBA, A., 2000: "El consumo de productos béticos en Valentia y su entorno: la continuidad de una larga tradición", Congreso $/ \mathrm{n}$ ternacional Ex Baetica Amphorae, II, Sevilla 1998, 565576. Écija.

REMESAL RODRÍGUEZ, J., 1986: La annona militaris y la exportación de aceite bético a Germania, Madrid.

TCHERNIA, A., 1964: "Amphores et marques d'amphores de Bétique à Pompéi et à Stabies", Mélanges de l'École Française de Rome. Antiquité, LXXVI, 419-499.

ZEVI, F., 1966: "Appunti sulle anfore romane. La tavola tipologica del Dressel”, Archeologia Clásica, XVIII, 208-247. 